\title{
Response to Wall and Brown: "Commercial pressures and professional ethics: troubling revisions to the recent ACOG Practice Bulletins on surgery for pelvic organ prolapse"
}

\author{
Anne M. Weber \\ Received: 8 August 2009 /Accepted: 12 August 2009 /Published online: 25 September 2009 \\ (C) The International Urogynecological Association 2009
}

\begin{abstract}
Dear Editor, I am responding to the recent Current Opinion/Update article by Drs. Wall and Brown [1]. As the author responsible for the controversial wording of the ACOG Practice Bulletin on pelvic organ prolapse, I would like to thank Drs. Wall and Brown for bringing the matter to the attention of clinicians, and Dr. Karram and the International Urogynecology Journal for their willingness to publish this.

The explanation I was given at the time why ACOG decided to change the wording (over my strenuous objections) was that the meaning of the word "experimental" was ambiguous. This is disingenuous at best. In fact, the ACOG staff member at the meeting of the Committee on Practice Bulletins-Gynecology described the real reason for concern: "...recognition that the current wording would possibly deny payment for some physicians." Most of the clinicians who objected to the use of the word "experimental" understood only too well exactly what meaning was intended - that the use of mesh kits as procedures for prolapse lacked sufficient evidence of risk versus benefit to adequately counsel patients as to expected outcomes. Such clinicians were concerned that insurance companies would not cover procedures labeled experimental, and they were concerned about their medicolegal risk should a complication arise in the course of procedures labeled experimental. Exactly the
\end{abstract}

Related correspondence can be found at doi:10.1007/s00192-0090983-x, doi:10.1007/s00192-009-0984-9, and doi:10.1007/s00192009-1003-x

A. M. Weber $(\bowtie)$

399 Wickford Drive,

Pittsburgh, PA 15238, USA

e-mail: aweber218@comcast.net kinds of concerns that a professional organization that truly promoted best medical practices would see as a red flag - that clinicians' concerns were not focused on what was best for the patient, but on what protected their income. That ACOG chose to align itself with these few Fellows at the expense of patients' outcome and safety is of grave concern.

If ACOG had actually decided that the meaning of the word "experimental" was ambiguous, it could have decided to clarify the meaning of the term in the document itself. As an alternative, ACOG could adopt an official definition of the term, as other professional organizations (such as the American Society for Reproductive Medicine) have done. That ACOG made neither of these choices underscores the real motivation behind deleting the term "experimental" from the Practice Bulletin.

I agree with Drs. Wall and Brown that ACOG can, and should, do better. Particularly given the heightened concern about complications with the mesh kits that prompted the FDA's public health advisory, as noted in the article by Drs. Wall and Brown, the appropriate action on the part of ACOG at this time is to restore the wording of the original Practice Bulletin, to emphasize the truly experimental nature of these procedures, and to stand behind its promise to women, in its own bylaws, by "serving as a strong advocate for quality health care for women, and maintaining the highest standards of clinical practice."

\section{References}

1. Wall LL, Brown D (2009) Commercial pressures and professional ethics: troubling revisions to the recent ACOG Practice Bulletins on surgery for pelvic organ prolapse. Int Urogynecol J 20:765-767. doi:10.1007/s00192-009-0864-3 